American Journal of Pharmaceutical Education 2017; 81 (9) Article 6241.

\title{
COMMENTARY
}

\section{An Approach for Some in Advanced Pharmacy Informatics Education}

\author{
Allen Flynn, PharmD, ${ }^{\text {a }}$ Brent I. Fox, PharmD, PhD, ${ }^{\mathrm{b}}$ Kevin A. Clauson, PharmD, ${ }^{\mathrm{c}}$ \\ Terry L. Seaton, PharmD, ${ }^{\mathrm{d}}$ Elizabeth Breeden, DPh, MS, \\ ${ }^{a}$ Department of Learning Health Sciences Medical School, University of Michigan, Ann Arbor, Michigan \\ ${ }^{\mathrm{b}}$ Harrison School of Pharmacy, Auburn University, Alabama \\ ${ }^{c}$ Lipscomb University College of Pharmacy and Health Sciences, Nashville, Tennessee \\ ${ }^{\mathrm{d}}$ St. Louis College of Pharmacy, St. Louis, Missouri \\ Submitted December 23, 2016; accepted May 14, 2017; published November 2017.
}

\begin{abstract}
Computerization is transforming health care while the quantity and complexity of biomedical knowledge rapidly grows. Today, all clinicians use health information technology (HIT), but only some pharmacists need to be cross-trained in "all" that advanced informatics entails so they can devise new and better information systems to support the pharmacy practice of the future. We propose a dual approach to informatics education in pharmacy: incorporate fundamental informatics education into pharmacy curricula for all students; and train some students interested in becoming informatics experts to design, develop, implement, and evaluate novel HIT for pharmacy. This commentary focuses specifically on the latter. It discusses the advanced pharmacy informatics training needed by some pharmacists to support innovation of HIT and to enable a shift to a more fully system-supported pharmacy practice.
\end{abstract}

Keywords: pharmacy informatics, education, standards, methods, health information technology

\section{BACKGROUND}

Informatics Education: Complementary Approaches

We propose two approaches to pharmacy informatics education based on the expectation that all PharmD students will practice in an environment supported by increasingly complex information systems ("Some training needed by all") while only some PharmD students will pursue informatics as the focus of their professional practice ("All training needed by some"). The first of these, informatics training needed by all PharmD students, is addressed in a previous commentary. ${ }^{1}$ The objective of this commentary is to describe the advanced training needed by some PharmD students who wish to become pharmacy informaticists. These individuals will be called on by the pharmacy profession to innovate and improve information tools and technologies so that pharmacy practice evolves into a system-supported ${ }^{2}$ practice of continuous learning as part of a larger effort to bring about a Learning Health System (LHS) for the U.S. and beyond. ${ }^{3}$

\section{Advanced Pharmacy Informatics Training Needed by Some}

Outlined here is an approach to teaching advanced pharmacy informatics concepts and skills - ie, teaching

Corresponding Author: Allen Flynn, $11^{\text {th }}$ Floor, 1161-C North Ingalls Building, University of Michigan, Ann Arbor, MI 48109. Tel: 734-615-0839. E-mail: ajflynn@umich.edu "all" that biomedical informatics entails - to a select number of student pharmacists while they are completing the PharmD curriculum. This approach to advanced pharmacy informatics training is intended to prepare these students sufficiently for further postgraduate informatics education, and is based on our projection that, during the next 10 years, between 600 and 1,800 pharmacy students and post-graduate pharmacists will seek residency and/or graduate-level training to help them become pharmacy informaticists (Table 1). The approach that follows emphasizes the types of expertise that future pharmacy informaticists will need to fully participate in the work of improving U.S. health information infrastructure, assisting pharmacy to develop an advanced, system-supported practice, and ultimately bringing about a Learning Health System. A Learning Health System is one in which data from most patient encounters are re-used for learning to continuously improve overall health system performance. ${ }^{3}$

\section{Motivation for Advanced Training in Informatics Concurrent with PharmD Studies}

What motivates the need for advanced informatics training for a select number of interested pharmacy students is the notion that the profession of pharmacy must improve its capabilities to advance pharmacy practice in an engineered world of automation and information systems. ${ }^{4}$ An argument that informatics is important to 


\section{American Journal of Pharmaceutical Education 2017; 81 (9) Article 6241.}

Table 1. Development of Estimates of the Size of Current and Future Pharmacy Informatics Workforce in the U.S.

\begin{tabular}{|c|c|c|c|}
\hline $\begin{array}{l}\text { Estimated Population or } \\
\text { Factor of Interest }\end{array}$ & Source(s) (Year) & $\begin{array}{l}\text { Point Estimates } \\
\text { from Source(s) }\end{array}$ & $\begin{array}{c}\text { Point Estimates for } \\
\text { this Paper }\end{array}$ \\
\hline $\begin{array}{l}\text { Pharmacists employed } \\
\text { in the U.S. }\end{array}$ & $\begin{array}{l}\text { U.S. Bureau of Labor } \\
\text { Statistics }(2014)^{23}\end{array}$ & $\begin{array}{l}290,780 \pm 2035 \\
( \pm \text { for RSE } 0.7 \%)\end{array}$ & 300,000 \\
\hline $\begin{array}{l}\text { U.S. community } \\
\text { pharmacists } \\
\% \text { of community pharmacist } \\
\text { time devoted to informatics }\end{array}$ & $\begin{array}{l}\text { National Pharmacist } \\
\text { Workforce Survey }(2015)^{24} \\
\text { National Pharmacist } \\
\text { Workforce Survey (2015) } \\
\text { U.S. Bureau of Labor } \\
\text { Statistics }(2015-16)^{25}\end{array}$ & $\begin{array}{l}183,000 \\
0.33 \text { of community } \\
\text { pharmacist time }\end{array}$ & \\
\hline $\begin{array}{l}\text { Community informatics } \\
\text { pharmacists, full-time }\end{array}$ & & & 595 \\
\hline $\begin{array}{l}\text { Number of non-specialty } \\
\text { hospitals in the U.S. }\end{array}$ & $\begin{array}{l}\text { American Hospital } \\
\text { Association }(2015)^{26}\end{array}$ & 5000 hospitals & \\
\hline $\begin{array}{l}\text { Average number of full-time } \\
\text { informatics pharmacists at hospitals } \\
\text { with } 50 \text { to } 500 \\
\text { beds }(n=3200)\end{array}$ & $\begin{array}{l}\text { American Hospital } \\
\text { Association }(2015)^{26} \\
\text { American Society of } \\
\text { Health-System Pharmacy National } \\
\text { Survey }(2008)^{27}\end{array}$ & 0.5 FTE & \\
\hline $\begin{array}{l}\text { Hospital informatics } \\
\text { pharmacists, full-time }\end{array}$ & & & 3100 \\
\hline $\begin{array}{l}\% \text { of other pharmacists working } \\
\text { full-time in pharmacy informatics }\end{array}$ & $\begin{array}{l}\text { National Pharmacist } \\
\text { Workforce Survey }^{24}(2015)\end{array}$ & $\begin{array}{l}1 \text { other pharmacist } \\
\text { working full-time in } \\
\text { pharmacy informatics }\end{array}$ & \\
\hline $\begin{array}{l}\text { Other informatics pharmacists, } \\
\text { full-time }\end{array}$ & & & 480 \\
\hline $\begin{array}{l}\text { Informatics pharmacists in } \\
\text { full-time roles today }\end{array}$ & & & $\begin{array}{c}4175 \pm 2088 \\
( \pm \text { for } \mathrm{EPE} 50 \%)\end{array}$ \\
\hline $\begin{array}{l}\text { Informatics pharmacists in full-time } \\
\text { roles by } 2025 \text {, } \\
\text { (growth } 1.15 \% / \text { year) }\end{array}$ & & & $\begin{array}{l}4681 \pm 2340 \mathrm{Ph} \\
( \pm \text { for } \mathrm{EPE} 50)\end{array}$ \\
\hline $\begin{array}{l}\text { Informatics } \\
\text { pharmacists in full-time roles } \\
\text { by } 2025 \\
\text { (growth } 3.45 \% / \text { year) }\end{array}$ & & & $\begin{array}{l}5861 \pm 2930 \mathrm{Ph} \\
( \pm \text { for } \mathrm{EPE} 50)\end{array}$ \\
\hline
\end{tabular}

$\mathrm{Ph}=$ Pharmacist FTE $=$ Full Time Equivalents; RSE $=$ Relative Standard Error; EPE $=$ Estimated Potential Error

medicine applies equally well to pharmacy. Informatics is no longer just a disciplinary priority for schools of engineering and computer science, but instead it is an area of focus in the process of becoming a disciplinary priority for both medical schools and pharmacy schools. ${ }^{2}$ Two interrelated steps must occur for informatics to become a disciplinary priority in pharmacy schools. First, faculty with interdisciplinary research interests spanning pharmacy, information, computer, and implementation sciences who appreciate the role biomedical informatics plays in supporting pharmacy practice must be hired and supported. Second, professional pharmacy programs must provide enough pharmacy students with the opportunity to work with these informatics faculty and develop themselves into the future pharmacy informatics workforce needed by the profession.

Our estimates indicate that the demand for informatics pharmacists will grow beyond the current rate of 


\section{American Journal of Pharmaceutical Education 2017; 81 (9) Article 6241.}

production over the next 10 years by a factor of 4 to 12 times (Table 1). Furthermore, by comparing training opportunities and credentialing requirements, we have reason to believe that many of today's informatics pharmacists are somewhat under-trained in biomedical informatics compared to their peers in nursing and medicine. ${ }^{5}$ Hence, the motivation to develop advanced informatics training opportunities for PharmD students is two-fold: the world needs more pharmacy informaticists and the informatics pharmacists in the world need to be trained in a more rigorous way.

\section{Proposed Advanced Pharmacy Informatics Curriculum Outline}

Based on prior reviews ${ }^{6-8}$ and additional evidence, ${ }^{9}$ we propose an advanced curriculum outline intended as a guide to train enough pharmacy informaticists over the next decade to support the shift to a systems-supported practice for pharmacy taking place within a Learning Health System. This curriculum outline covers the necessary aspects of the domain of biomedical informatics to prepare enough pharmacy informaticists to participate effectively in four general categories of informatics work. This preparation may be completed before, during, and/or after formal pharmacy education. However, in order to bring prospects interested in informatics into pharmacy schools, and because of the large scope of this advanced training in informatics, the importance of enabling students to start informatics training during pharmacy school cannot be overemphasized. The following four categories span the areas of expertise in biomedical informatics that pharmacy informaticists need to understand to bring about better health information technology (IT) systems for pharmacy: design and modeling of information systems, development of prototypes, implementation of health IT, and evaluation of health information resources. ${ }^{10}$

Being competent in all four categories is necessary to collaborate effectively with data and information scientists, computer scientists and programmers, and other pharmacists as an advanced pharmacy informaticist. The goal of advanced education in pharmacy informatics should be to gain balanced coverage of the four categories of informatics work above. ${ }^{10}$ To cover the required material in sufficient depth and to provide students with enough experience, just as it is in medicine, it is assumed that some graduate level study will be required for pharmacy informaticists. Table 2 provides a high-level overview of what is included in the four categories of biomedical informatics expertise listed above. Table 3 provides recommended approaches with resources for all four content categories for pharmacy educators who wish to teach advanced topics in pharmacy informatics, described below.

\section{Design and Modeling of Information Systems}

Before health information systems can be developed, detailed models of the information to be processed by each system must be created. These information models need to be logically consistent and capable of supporting end-users in practice. Often these information models will need to be developed collaboratively within communities of shared interest so that the models can become industry standards. ${ }^{11,12}$ Pharmacy informaticists must not only be aware of information modeling but must also be able to participate meaningfully in collaborative information modeling activities. In addition to information modeling, pharmacy informaticists need to gain experience in other types of design work. Health application user interface designs and visualizations, especially for use in systems that process and display medication-related information, can be created and improved by pharmacy informaticists. Pharmacy informaticists also need to be able to design new workflows, software manuals, implementation guides and software training programs.

\section{Development of Prototypes}

In our engineered, human-made, "artificial world" of many information systems, ${ }^{4}$ to have a lasting impact in pharmacy informatics requires informatics specialists to participate meaningfully in making applications and systems to support an evolving pharmacy practice. While there are many facets of pharmacy informatics and many areas in which to specialize, a necessary expectation for advanced pharmacy informaticists is to be able to program a computer well enough to demonstrate new and potentially better methods of organizing, using, and displaying information. ${ }^{13}$ Here it is important to distinguish the work of pharmacy informaticists from the work of professional programmers. Professional programmers apply computer science principles to develop new applications and systems for widespread deployment. While some pharmacy informaticists are also professional programmers, it is not necessary or desirable for all pharmacy informaticists to become professional programmers. Instead, we recommend that advanced pharmacy informaticists develop the capability to communicate their ideas in the form of software code and to create working prototypes of potential new applications and systems. ${ }^{10}$ Once prototypes have been developed, pharmacy informaticists can use them to more easily and effectively collaborate with professional programmers in building production IT systems. This prototype development work anchors pharmacy informaticists in both the possibilities 
American Journal of Pharmaceutical Education 2017; 81 (9) Article 6241.

Table 2. Four Categories of Biomedical Informatics Expertise

\begin{tabular}{lc}
\hline Category & Specific Areas of Expertise \\
\hline $\begin{array}{l}\text { Design and Modeling of } \\
\text { Information Systems }\end{array}$ & $\begin{array}{c}\text { Complex systems, Databases, Design principles, Human factors, Information modeling, IT } \\
\text { infrastructures, Knowledge-representation, Ontologies, Terminologies, User experience, } \\
\text { Wire-framing }\end{array}$ \\
Development of Prototypes & $\begin{array}{c}\text { Application frameworks and platforms, Computer logic, Programming System administration, } \\
\text { Technical writing }\end{array}$ \\
Implementation of Health IT & $\begin{array}{c}\text { Business process analysis, Change management, Communication, Human psychology, } \\
\text { Innovation, Interoperability, Instructional design, Organizational behavior, Project }\end{array}$ \\
management, System integration, System performance
\end{tabular}

and constraints of actual information technologies so that they can knowledgeably consider how best to meet pharmacists' needs.

\section{Implementation of Health IT}

Implementation of new or modified information systems involves helping individuals and groups to adapt and successfully change their policies and practice. This work requires well-developed skills for organizing, motivating others, communicating, managing projects, and providing leadership to bring about effective change. ${ }^{14}$ The process of implementing new or improved medication-use information systems and other HIT often begins with business process analysis to define both the current and intended future state workflows. Using this business process information, pharmacy informaticists need to develop the skills to successfully bring about system-enabled changes to pharmacy practice. Almost without exception, implementing new systems involves tradeoffs, and, especially at first, these tradeoffs often inspire resistance to change within organizations. ${ }^{15}$ Advanced training for pharmacy informaticists therefore needs to include skill-building and practice managing and communicating about change, tracking of problems, identifying solutions and then reporting on progress made toward improvements to system users and leadership.

\section{Evaluation of Health Information Resources}

Once systems are implemented, it is imperative to learn about their impact through thoughtful evaluation. Today, many organizations need experts to evaluate the impact of information systems on an ongoing basis. Evaluation work can involve conducting both qualitative and quantitative studies. ${ }^{16}$ The work involved in evaluating information resources has as its goal to determine and communicate the nature and scope of impact from the implementation and use of information systems. At times, even before an evaluation can be undertaken, pharmacy informaticists will need to develop their own reliable and valid measures of potential impacts of interest. Once measurement and evaluation studies are completed, they can add to the scientific body of knowledge in pharmacy informatics. In fact, much of the scientific work published in informatics journals is the work of evaluation. ${ }^{17}$ However, HIT evaluation studies must also be done more informally to guide HIT-related efforts within organizations. ${ }^{16}$

\section{THE IMPORTANCE OF HAVING A SYSTEM- SUPPORTED PRACTICE WITHIN A LEARNING HEALTH SYSTEM}

What is needed for the foreseeable future are pharmacy informaticists trained to work effectively with modular, scalable information systems and service-based health IT infrastructures to support ongoing and accelerating learning processes about medication-use and human health. ${ }^{18}$ While anxieties over automation persist throughout society, ${ }^{19}$ there is reason to believe that a better, system-supported practice for pharmacy is in the offing, and that pharmacists could be greatly empowered by it to help patients more consistently and effectively to achieve their health goals. ${ }^{20}$ In a recently published 10 -year vision statement, the U.S. Office of the National Coordinator for Health Information Technology described a path toward creating a nationwide Learning Health System (LHS) by 2025..$^{21}$ Even more recently, the Food and Drug Administration has begun to seriously explore the possibilities of using real-world data about consumers to augment learning from clinical trials under the banner of Evidence Generation or "EvGen" (blogs.fda.gov). Pharmacy informaticists with advanced training are needed to help with these and 


\section{American Journal of Pharmaceutical Education 2017; 81 (9) Article 6241.}

Table 3. Advanced Training Educational Recommendations

\begin{tabular}{lc}
\hline Domain and Purpose & Recommended Educational Materials and Approaches \\
\hline \begin{tabular}{l} 
General Informatics \\
\hline Useful guides
\end{tabular} & Use Springer Health Informatics series, www.springer.com/series/1114?detailsPage=titles \\
Structured health data & Try National Library of Medicine's RxNorm and RxNav, www.nlm.nih.gov/research/umls/ \\
& rxnorm/ \\
Standards development & Examine Structured Product Labeling resources from the Food and Drug Administration and \\
& NLM \\
Standards development & Study NCPDP work on standards, as represented online here, www.ncpdp.org/Education/ \\
Phitepaper & Discuss Pharmacy Health Information Technology Collaborative, http://www.pharmacyhit. \\
org/
\end{tabular}

$\underline{\text { Design and Modeling of }}$ Information Systems User-interface design User-interface design Data modeling Information modeling

Information modeling

Use "Elements of User Experience" by Garrett JJ, www.jjg.net/elements/ Try free online wireframing tools, such as fluid, www.fluidui.com/ Examine Fast Health Interoperability Resources from HL7, www.hl7.org/fhir/ Use "Semantic Web for the Working Ontologist" by Allemang D, Hendler J, workingontologist.org/

Use Protégé and ontologies collected by the National Center for Biomedical Ontology to inspect existing and create biomedical ontologies, protege.stanford.edu/ and www. bioontology.org/

$\underline{\text { Development of Prototypes }}$ Programming

Application development

Application development

Take a step-wise approach that begins with spreadsheets, then databases, then web pages with www.w3schools.com, and finally ends with the study of programming languages like Python, www.python.org and PERL, www.perl.org

Use free online tutorials for web application frameworks such as Django, www.djangoproject. com/ or Spring Boot projects.spring.io/spring-boot/

Develop a web app that makes use of readily available enabling technologies on the World Wide Web such as SMART, docs.smarthealthit.org/, and open FHIR servers, wiki.hl7.org/ index.php?title=Publicly_Available_FHIR_Servers_for_testing

Implementation of Health IT Implementation science

Study dissemination and implementation research in health, such as accelerate.ucsf.edu/files/ CE/edi_introguide.pdf

Workflow modeling

Practice workflow business practice modeling in a pharmacy context, as workflow modeling is described here, creately.com/blog/diagrams/business-process-modeling-tutorial/

Real-world experience

Work with members of an electronic health record (EHR) team in a health organization to implement a change

Evaluation of Health Information

Resources

Evaluation science

Use "Evaluation Methods in Informatics" by Friedman CP, Wyatt J at www.springer.com/us/ book/9780387258898

Heuristic evaluation

Perform a heuristic evaluation of usability of an existing medication use system or medicationrelated app according to the guidelines here, www.nngroup.com/articles/how-to-conduct-aheuristic-evaluation/

Measurement

Administer an end-user satisfaction survey for a medication-use system using a validated scale like, Doll WJ, Torkzadeh G. The measurement of end-user computing satisfaction. MIS Quarterly. 1988;12(2):259-274.

Abbreviations: NLM = National Library of Medicine; NCPDP = National Council for Prescription Drug Programs; HL7 = Health Level 7; SMART $=$ Substitutable Medical Applications and Reusable Technologies; FHIR = Fast Health Interoperability Resources; EHR = Electronic Health Record 


\section{American Journal of Pharmaceutical Education 2017; 81 (9) Article 6241.}

other similar or related national efforts, especially because many questions a nationwide LHS must answer focus on medication use. ${ }^{22}$

\section{CONCLUSION}

In two related commentaries, we argue for a dual approach to informatics education in pharmacy, an approach that recognizes all PharmD students need some training in informatics and also recognizes that some PharmD students need to begin advanced informatics training while they are student pharmacists. This paper provides details about what that advanced informatics training entails, and makes the point that advanced training covers four categories of the biomedical informatics domain: design, development, implementation, and evaluation of new and potentially better systems to support pharmacy practice.

\section{REFERENCES}

1. Fox BI, Flynn A, Clauson KA, Seaton TL, Breeden E. An approach for all in pharmacy informatics education. Am J Pharm Educ. 2017. 81(2): Article 38.

2. Stead WW, Searle JR, Fessler HE, Smith JW, Shortliffe EH. Biomedical informatics: changing what physicians need to know and how they learn. Acad Med. 2011;86(4):429-434.

3. Friedman C, Rigby M. Conceptualising and creating a global learning health system. Int J Med Inform. 2013;82(4):e63-e71.

4. Simon HA. The Sciences of the Artificial. 3rd ed. Cambridge, MA: MIT Press; 1996.

5. Gadd CS, Williamson JJ, Steen EB, Fridsma DB. Creating advanced health informatics certification. J Am Med Inform Assoc. 2016;23(4):848-850.

6. Fox BI, Flynn AJ, Fortier CR, Clauson KA. Knowledge, skills, and resources for pharmacy informatics education. Am J Pharm Educ. 2011;75(5):Article 93.

7. Flynn AJ. The current state of pharmacy informatics education in professional programs at US colleges of pharmacy. Am J Pharm Educ. 2005;69(4):Article 66.

8. Fox BI, Karcher RB, Flynn A, Mitchell S. Pharmacy informatics syllabi in doctor of pharmacy programs in the US. Am J Pharm Educ. 2008;72(4):Article 89.

9. Shortliffe E, Cimino J, eds. Biomedical Informatics: Computer Applications in Health Care and Biomedicine. New York, NY: Springer; 2006.

10. Friedman CP. Where's the science in medical informatics? $J A m$ Med Inform Assoc. 1995;2(1):65-67.

11. Bender D, Sartipi K. HL7 FHIR: An Agile and RESTful approach to healthcare information exchange. Paper presented at the Proceedings of the 26th IEEE International Symposium on Computer-Based Medical Systems; June 20-22, 2013.
12. Friedman MA, Schueth A, Bell DS. Interoperable electronic prescribing in the United States: a progress report. Health Aff (Millwood). 2009;28(2):393-403.

13. Friedman CP. A 'fundamental theorem' of biomedical informatics. J Am Med Inform Assoc. 2009;16(2):169-170.

14. Cresswell KM, Bates DW, Sheikh A. Ten key considerations for the successful implementation and adoption of large-scale health information technology. J Am Med Inform Assoc. 2013;20(e1):e9e13.

15. Conn J. Training key to rollout, Cedars-Sinai exec says. 2012. http://www.modernhealthcare.com/article/20121017/NEWS/ 310179997. Accessed December 7, 2016.

16. Friedman CP, Wyatt J. Evaluation Methods in Biomedical Informatics. 2nd ed. New York, NY: Springer; 2006.

17. Talmon J, Ammenwerth E, Brender J, de Keizer N, Nykänen P, Rigby M. STARE-HI-Statement on reporting of evaluation studies in Health Informatics. Int J Med Inform. 2009;78(1):1-9.

18. Greene SM, Reid RJ, Larson EB. Implementing the learning health system: from concept to action. Ann Intern Med. 2012;157 (3):207-210.

19. Mokyr J, Vickers C, Ziebarth NL. The history of technological anxiety and the future of economic growth: is this time different? $J$ Econ Perspect. 2015;29(3):31-50.

20. Zulman DM, Shah NH, Verghese A. Evolutionary pressures on the electronic health record: caring for complexity. JAMA. 2016;316 (9):923-924.

21. Office of the National Coordinator for Health Information Technology. Connecting health and care for the nation: a shared nationwide interoperability roadmap - version 1.0. 2015; https:// www.healthit.gov/buzz-blog/electronic-health-and-medical-records/ interoperability-electronic-health-and-medical-records/connectinghealth-care-nation-shared-nationwide-interoperability-roadmapversion-10/. Accessed February 12, 2016.

22. Institute of Medicine. Best Care at Lower Cost: The Path to Continuously Learning Health Care in America. Washington, DC: The National Academies Press; 2013.

23. Bureau of Labor Statistics. Occupational employment and wages, May 2014, 29-1051 pharmacists. 2014; http://www.bls.gov/ oes/current/oes291051.htm. Accessed December 30, 2015.

24. Gaither CA SJ, Doucette WR, Kreling DH, Mott DA. 2014 National pharmacist workforce survey. 2015; http://www.aacp.org/ resources/research/pharmacyworkforcecenter/Documents/ FinalReportOfTheNationalPharmacistWorkforceStudy2014.pdf. Accessed February 12, 2016.

25. Bureau of Labor Statistics. Occupational outlook handbook, 2015-16 edition, pharmacists. 2015; http://www.bls.gov/ooh/ healthcare/pharmacists.htm. Accessed September 30, 2015. 26. American Hospital Association. Fast facts on US hospitals. 2015; http://www.aha.org/research/rc/stat-studies/fast-facts2015.shtml. Accessed February 10, 2016.

27. Pedersen CA, Schneider PJ, Scheckelhoff DJ. ASHP national survey of pharmacy practice in hospital settings: spensing and administration - 2008. Am J Health Syst Pharm. 2009;66(10): 926-946. 